\title{
O SIGNIFICADO ARQUEOLÓGICO DOS DEPÓSITOS TECNOGÊNICO-ALUVIAIS DA BACIA DO RIO UNA (TAUBATÉ, SP).
}

\author{
Alex Ubiratan Goossens Peloggia ${ }^{1}$ \\ alexpeloggia@uol.com.br
}

\section{Resumo}

Os depósitos sedimentares antropogênicos caracterizados como Aloformação Rio Una, que configuram baixos terraços ao longo dos vales do rio citado e seus afluentes, na região rural de Taubaté (SP), são registros geológicos correlativos do processo de degradação ambiental derivado da derrubada da Mata Atlântica e implantação dos cultivos de café em meados do século XIX. Argumenta-se que tais formações geológicas, como produtos indiretos da ação humana, são os principais vestígios materiais preservados do referido episódio de apropriação do relevo, e refletem, em suas características sedimentares e geomorfológicas anômalas, a particularidade da relação humanidade-natureza no contexto histórico-cultural considerado.

Palavras-chave: depósitos antropogênicos (tecnogênicos), Aloformação Rio Una, Taubaté, Ciclo do Café, geoarqueologia.

\begin{abstract}
The anthropogenic sedimentary deposits, named Rio Una Alloformation, which configures low terraces along the valleys of the cited river and its tributaries in Taubaté (SP) countryside, are correlative geological records of environmental degradation derived from the overthrow of the Atlantic Forest and deployment of coffee crops in the mid-nineteenth century. We argue that such geological formations, as indirect products of human action, are the main preserved material remains of that relief appropriation episode, and reflect on their sedimentary and geomorphological anomalous characteristics the particularities of the humankind-nature relationship in the considered historic cultural context.
\end{abstract}

Keywords: anthropogenic (technogenic) deposits, Rio Una Alloformation, Taubaté, Coffee Cycle, geoarchaeology.

\footnotetext{
Résumé

Les dépôts sédimentaires anthropiques caractérisés comme Aloformation Rio Una, qui configurent basses terrasses le long des vallées de ladite rivière et de ses affluents en milieu rural dans Taubaté (SP), sont des enregistrements géologiques corrélatifs de la dégradation de l'environnement provenant du renversement de la Forêt Atlantique et du déploiement de la culture du café au milieu du XIXe siècle. II est soutenu que ces formations géologiques, tels que produits indirects de l'action humaine, sont les principaux vestiges matériaux préservés de ce l'épisode de occupation des versants, et que leurs caractéristiques sédimentologiques et géomorphologiques anormales indiquent las particularités de la relation humanité-nature dans le contexte historique culturelle considéré .

Mots-clés: dépôts anthropiques (technogéniques), Aloformation Rio Una, Taubaté , Cycle du Café, géoarchéologie.

${ }^{1}$ Geólogo e Psicanalista. Prof. Dr. do Programa de Mestrado em Análise Geoambiental da Universidade de Guarulhos e membro do Grupo de Estudos do Antropoceno e do Tecnógeno - UnG. alexpeloggia@uol.com.br.
}

(C) Rev. Arqueologia Pública

\begin{tabular}{l|l} 
Campinas, SP & v.9
\end{tabular} No.(11) \begin{tabular}{|l|l}
\hline p.207-219 & suplemento \\
\hline
\end{tabular} 


\section{Introdução}

Alguém que observe hoje a paisagem de morros e serras alongadas do vale do rio Una, afluente da margem direita do Paraíba do Sul ao sul da cidade de Taubaté (SP), entre esta cidade e São Luís do Paraitinga, possivelmente não imaginará as dramáticas transformações paisagísticas ocorridas em tempos históricos recentes. Ao observador comum, as vertentes em geral recobertas da vegetação rasteira rala dos pastos degradados, cortadas aqui e ali por cicatrizes de escorregamentos rasos ou sulcos de erosão recente, podem parecer uma fisionomia tão antiga quanto qualquer outra. Mesmo uma observação mais acurada pode não encontrar aspectos evidentes de transformação, uma vez que não há restos de fazendas antigas (comuns em outras porções do Vale do Paraíba) ou outros vestígios de diferentes tipos de ocupação.

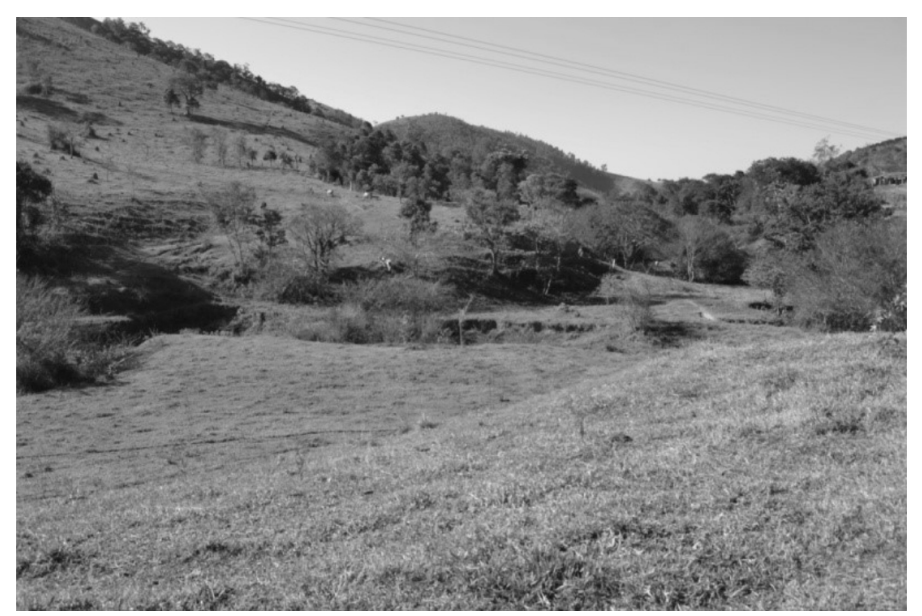

Figura 1. Aspecto da paisagem atual da bacia do rio Una e de seu afluente ribeirão das Sete Voltas (foto do autor, 2014).

Todavia, a observação geomorfológica permite-nos perceber, em primeira mão, que há "algo errado" com a evolução da paisagem local: nos fundos de vale há uma forma de relevo contínua e extremamente regular, um "baixo terraço aluvial" sustentado por um pacote arenoso de até $5 \mathrm{~m}$ de espessura observada, registrado nos mapas geológicos como sedimentos de idade quaternária. Este terraço está sofrendo um processo de incisão do

v.9

No.(11)

p.207-219 suplemento 
próprio canal, que em certos pontos aprofundou seu leito a ponto de alcançar o substrato (solos de alteração de rochas pré-cambrianas) e mesmo exumar antigas cachoeiras, o que indica um processo ativo de reajustamento da drenagem local.

A investigação geológica dessa formação sedimentar fornece a chave para o entendimento da gênese do terraço (CAPELLARI E PELOGGIA, 2012; PELOGGIA et al., 2015): tratam-se na verdade de camadas tecnogênico-sedimentares muito recentes e anômalas em relação a fatores geológicos naturais controladores dos processos deposicionais (tectônica e clima), mas que se explicam como resultado da interação do homem com a paisagem (erosão acelerada e sedimentação induzida).

\section{Os terrenos tecnogênicos de agradação}

Os geólogos têm denominado de terrenos artificiais ou tecnogênicos ou antropogênicos ao conjunto de depósitos, solos ou configurações de relevo produzidas direta ou indiretamente pela ação humana. Nesse contexto, é possível classificar os terrenos tecnogênicos em quatro classes básicas: terrenos tecnogênicos de agradação (formações superficiais antropogênicas e formas de relevo associadas), de degradação (formas de relevo derivadas da retirada ou movimentação induzida de material geológico), modificados (solos tecnogênicos, formados in situ) e mistos (sequências tecnogênicas) (PELOGGIA et al. 2014a). Dentre os terrenos tecnogênicos de agradação, resultantes da acumulação de material geológico, podem ser diferenciados os seguintes tipos:

Quadro 1. Classificação geral dos terrenos tecnogênicos de agradação (adaptada e ampliada de Peloggia et al. 2014a).

\begin{tabular}{|c|c|c|c|}
\hline CLASSE & $\begin{array}{l}\text { CATEGORIA } \\
\text { GEOLÓGICA }\end{array}$ & TIPO & CAMADA OU FEIÇÃO TECNOGÊNICA \\
\hline \multirow{6}{*}{ 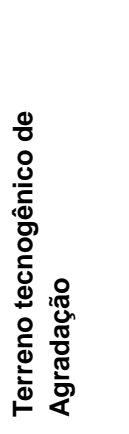 } & \multirow{6}{*}{ 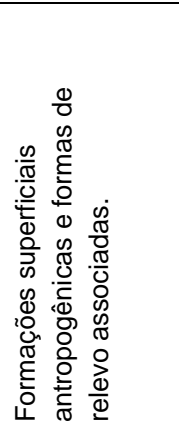 } & Terreno produzido & Depósitos tecnogênicos construídos (aterrados) sobre terreno natural \\
\hline & & Terreno preenchido & $\begin{array}{l}\text { Depósitos tecnogênicos construídos de preenchimento recobrindo terreno } \\
\text { escavado ou erodido. }\end{array}$ \\
\hline & & Terreno acumulado & Depósitos tecnogênicos ocupacionais \\
\hline & & $\begin{array}{l}\text { Terreno } \\
\text { tecnogênico } \\
\text { sedimentar alluvial }\end{array}$ & $\begin{array}{l}\text { Depósitos tecnogênico-sedimentares induzidos de tipo aluvial, ou tecnogênico- } \\
\text { aluviais. }\end{array}$ \\
\hline & & $\begin{array}{l}\text { Terreno } \\
\text { tecnogênico } \\
\text { sedimentar coluvial }\end{array}$ & $\begin{array}{l}\text { Depósitos tecnogênicos-sedimentares induzidos de tipo coluvial, ou } \\
\text { tecnogênico-coluviais. }\end{array}$ \\
\hline & & $\begin{array}{l}\text { Terreno } \\
\text { remobilizado }\end{array}$ & $\begin{array}{l}\text { Depósitos tecnogênicos remobilizados formados por erosão e redeposição de } \\
\text { depósitos preexistentes. }\end{array}$ \\
\hline
\end{tabular}

\begin{tabular}{|l|l|l|l|l|l|l|}
\hline (C Rev. Arqueologia Pública & Campinas, SP & v.9 & No.(11) & p.207-219 & suplemento & ISSN 2237-8294 \\
\hline
\end{tabular} 
No entanto, as abordagens divergem em sua caracterização: por exemplo, a classificação dos terrenos artificiais do Serviço Geológico Britânico trabalha somente com terrenos de agradação (made ground e infilled ground, isto é, terrenos produzidos ou preenchidos) decorrentes da ação humana direta em sua deposição, enquanto que em países de colonização (e consequente uso intensivo do solo) recente, como o Brasil e os Estados Unidos da América, recai interesse nos depósitos chamados de induzidos, ou seja, resultantes indiretos da ação humana (esta que altera condições de erodibilidade e erosividade, do que decorre sedimentação correlativa).

Os depósitos tecnogênico-sedimentrares aluviais têm sido estudados no Brasil notadamente a partir da década de 1990, e sua correlação com as mudanças do uso e ocupação do solo (desmatamento, práticas agrícolas, mineração, urbanização) têm sido evidenciada (e.g. OLIVEIRA 1990, OLIVEIRA et al. 2005). Nos Estados Unidos, o surgimento dessas camadas antropogênicas (denominadas de post settlement alluvium ou legacy sediments, quer dizer, aluviões pós-ocupação ou sedimentos herdados) também tem sido relacionados a processos agrícolas e de mineração (e.g. HAPP et al. 2008 [1940], ROEHL E HOLEMAN 1975, JAMES 2013). Tais depósitos são correspondentes aos que Borja Barrera (1993), no campo da geoarqueologia e utilizando o conceito de formação superficial correlativa, classifica como formações antrópicas induzidas, ou seja, geradas em decorrência de processos geomorfológicos acelerados e identificadas a partir da comparação com sequências naturais.

\section{Caracterização geológica e geomorfológica dos depósitos}

Os depósitos antropogênicos da bacia rio Una, estudados e mapeados em escala 1:10.000 (PELOGGIA et al., 2015) (figura 2), formam terrenos tecnogênicos de agradação distribuídos de forma irregular, porém contínua, ao longo dos fundos de vale, configurando a forma de relevo característica de baixos terraços (ou seja, superfícies planas produzidas pela acumulação do material por sedimentação induzida, conforme proposta de classificação de Peloggia et al. 2014b) (figura 3). Tais terraços foram posteriormente erodidos pela incisão do próprio canal fluvial, o que configurou a morfologia meândrica atual.

(C) Rev. Arqueologia Pública \begin{tabular}{l|l} 
Campinas, SP & v.9
\end{tabular} \begin{tabular}{|l|l|l} 
No.(11) & p.207-219 & suplemento \\
\hline
\end{tabular} ISSN 2237-8294 
느 II SEMANA DE

O ARQUEOLOGIA

N DA UNICAMP

ATAS

HISTÓRIA E CULTURA MATERIAL: DESAFIOS DA CONTEMPORANEIDADE
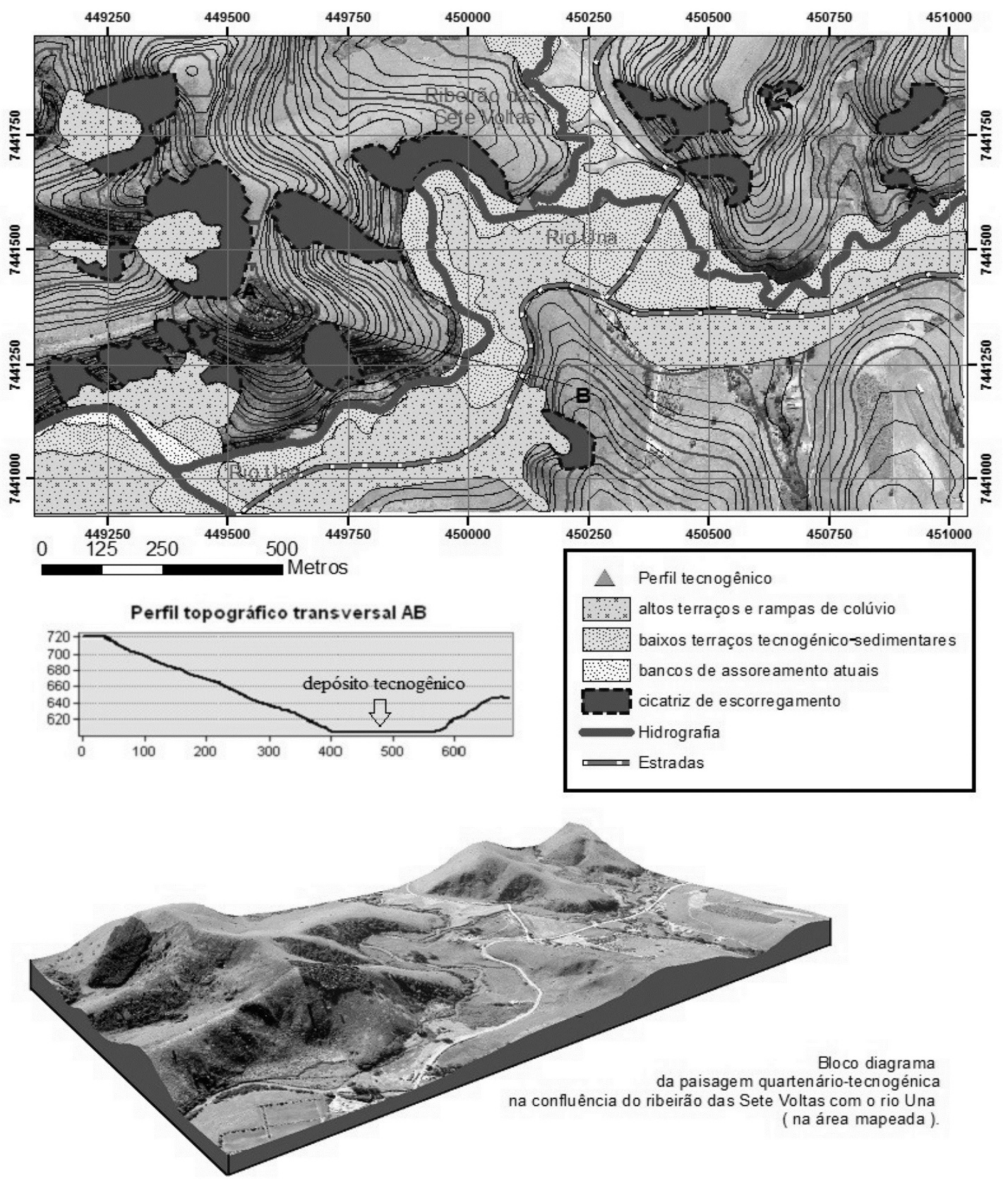

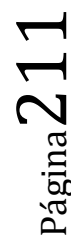

Vo

( na área mapeada )

(C) Rev. Arqu 
Figura 2. Formações superficiais e relevo da área estudada em detalhe (PELOGGIA et al. 2015).

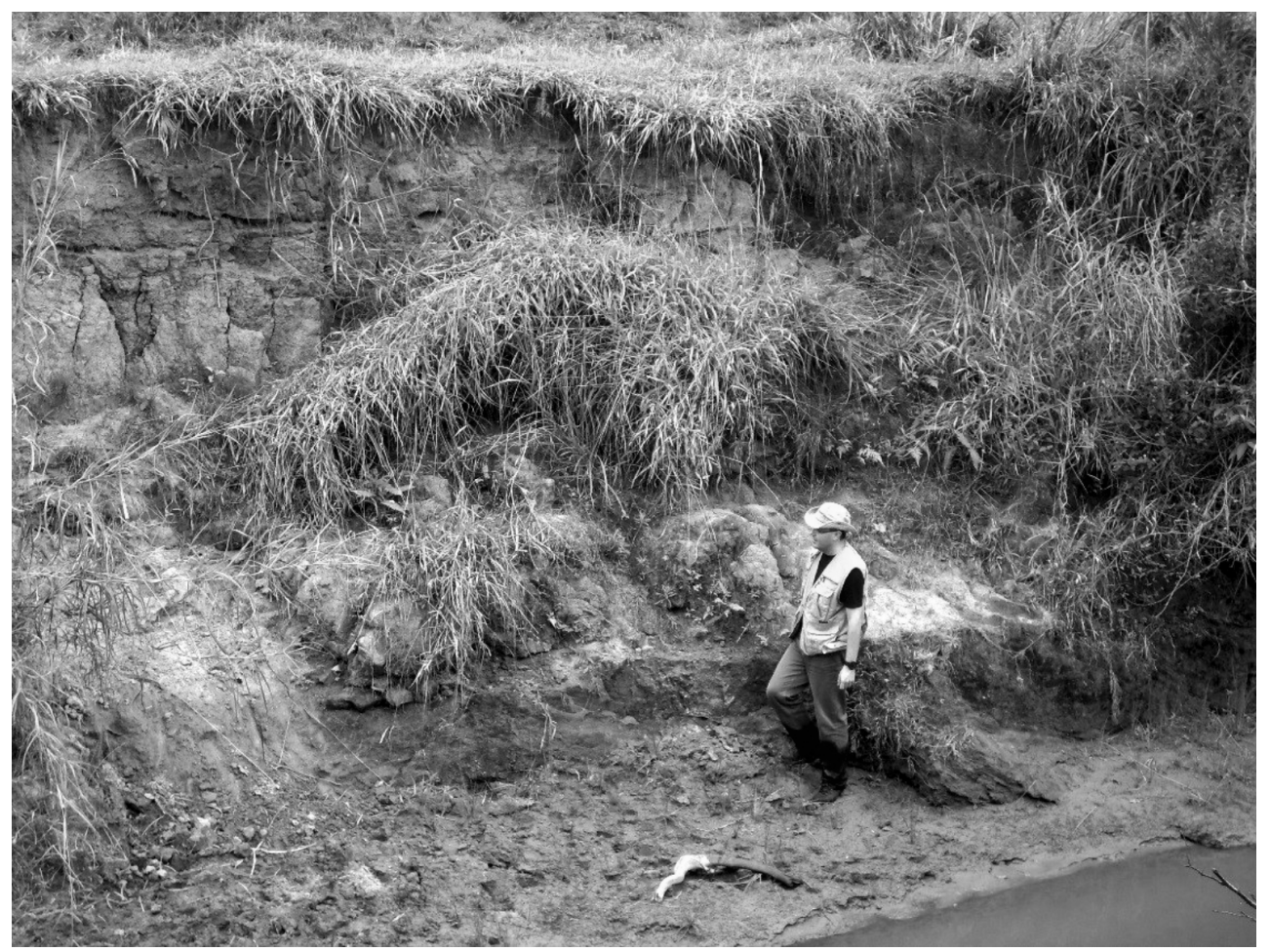

Figura 3. Baixos terraços aluviais no fundo do vale do Una-Sete Voltas (foto do autor, 2014).

Os sedimentos tecnogênicos que sustentam os baixos terraços caracterizam-se por forte imaturidade textural e mineralógica que, em associação com a textura predominantemente grossa e as estruturas sedimentares observadas (figura 3 ), indicam um processo deposicional intenso e episódico, no qual uma quantidade anômala de sedimentos proveio de um processo erosivo acelerado nas vertentes da bacia, erosão esta que atingiu e desgastou níveis inferiores ao solo superficial e assoreou os fundos de vale. Os níveis basais do perfil estudado sugerem a possibilidade de ocorrência de processos iniciais de fluxos de detritos, seguidos pela reorganização do canal para o padrão entrelaçado (braided). Tais processos sedimentares, no registro geológico natural, são usualmente associados a mudanças climáticas ou atividade neotectônica.

v.9

No.(11)

p.207-219 suplemento

ISSN 2237-8294 


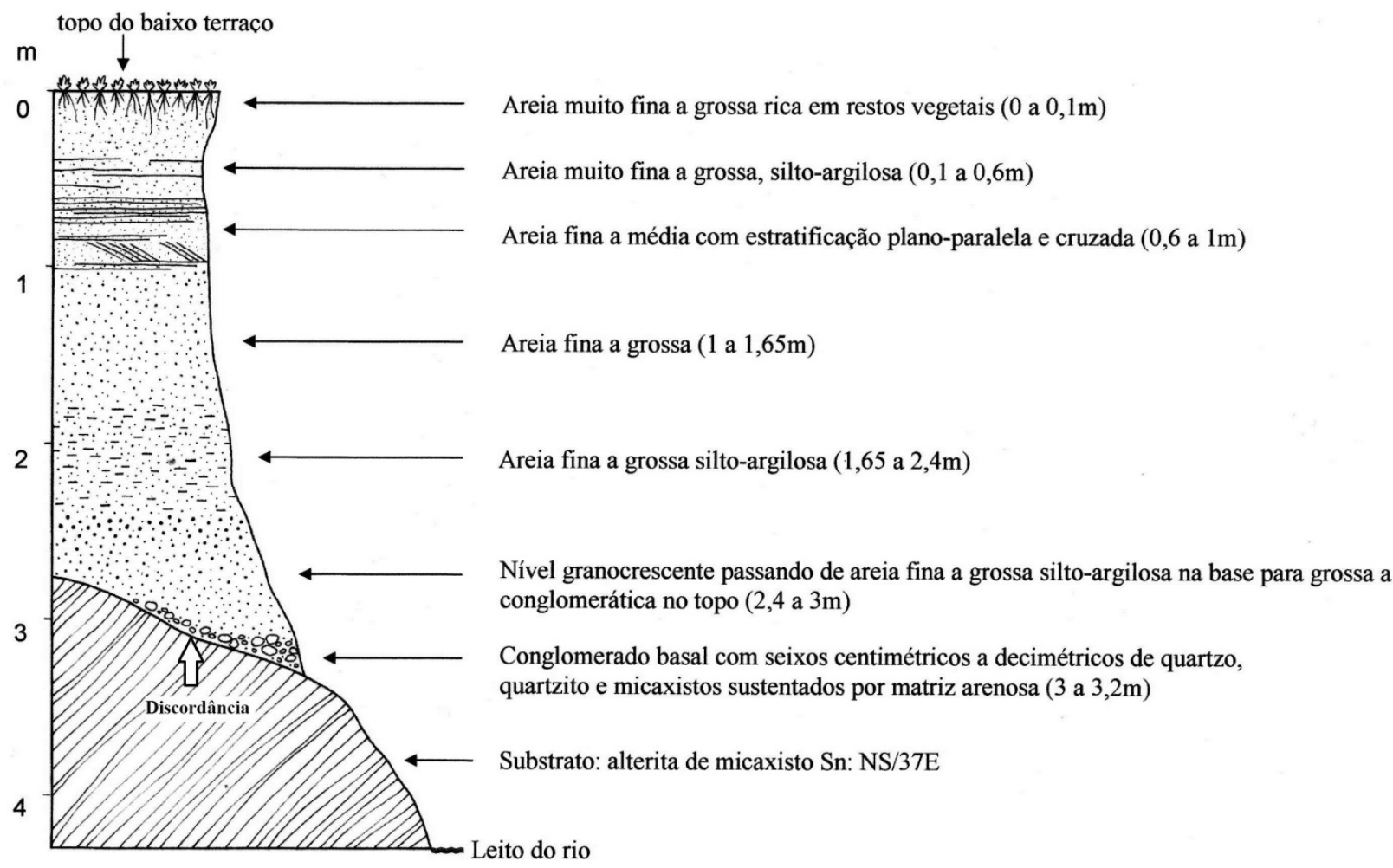

Figura 4. Perfil geológico do depósito tecnogênico visto na figura 3, cuja localização é indicada na figura 2 (PELOGGIA et al. 2015).

Em síntese, os depósitos tecnogênico-aluviais da bacia do Rio Una são formações geológicas superficiais antropogênicas, provavelmente correlativas de um processo de resistasia antrópica de degradação das vertentes por supressão da mata original, que relacionamos ao contexto da expansão do plantio do café no Vale do Paraíba, cujas consequências ambientais e geológicas já têm sido extensamente descritas em sua porção leste por outros pesquisadores (e.g. DEAN, 1996; COELHO-NETTO, 1999) .

O uso da categoria de aloformação para tais depósitos é aqui considerado conveniente, pois atende aos requisitos de mapeabilidade, definição de limites (descontinuidades laterais e superfícies) e definição de características internas. Do ponto de vista temporal, adotou-se a proposta de Oliveira e Peloggia (2014), que consiste na utilização das unidades diacrônicas previstas nos Códigos Estratigráficos Norte-americanos de 1983 e 2005 (NACSN, 2005), aqui definidas em uma escala temporal geotecnogênica. Nesse 
enquadramento, os depósitos considerados devem corresponder ao Antropoceno, entendido como fase mais recente do evento Tecnógeno. Do ponto de vista geocronológico, correspondem a depósitos do topo do Holoceno, e portanto do Quaternário.

A posição geomorfológica e a idade recente dos depósitos permitem correlacioná-los, no contexto do Vale do Paraíba do Sul, à aloformação Resgate, formada por depósitos tecnogênico-aluviais descritos na região de Bananal (SP/RJ) e datados por radiocarbono em 130+/-60 anos A.P. e 240+/-50 anos A.P. (MOURA E MELLO, 1991; MOURA et al. 1992, MELLO et al. 1995), embora possivelmente os depósitos de Taubaté sejam até algumas décadas mais jovens, em função da expansão do Ciclo Cafeeiro. Acreditamos ser possível englobar a aloformação Resgate e a aloformação Rio Una em um alogrupo, para o qual se sugere a denominação Alogrupo Ciclo do Café no Vale do Paraíba. Esta denominação tem como fundamento o caráter correlativo dos depósitos tecnogênicos/antropogênicos, que permite identificar o episódio de apropriação do território e transformação da paisagem geneticamente associado, como tem sido feito pelo Serviço Geológico Britânico (FORD et al. 2014).

\section{Significado Arqueológico}

Como tal interação decorre sempre em contextos históricos específicos, como acreditamos ser o caso, tais depósitos tecnogênico-aluviais têm, também, um caráter arqueológico definido: representam e podem indicar aspectos do modo de viver (particularmente a relação com o ambiente) e mesmo de pensar das pessoas que indiretamente os produziram.

Argumentamos que tais depósitos foram produzidos durante o Ciclo do Café na região de Taubaté, em meados do século XIX. Já foi mostrado que tal ciclo econômico promoveu uma crise ambiental significativa, em função do desmatamento e das práticas agrícolas inadequadas (por exemplo, o plantio dos renques de cafeeiros em linhas dispostas segundo a maior declividade das encostas) que refletiam não necessariamente desconhecimento, mas notadamente uma forma própria de produção econômica (DEAN, 1996; LIMA, 2003, MARTINEZ, 2010; GUIMARÃES, 2010).

Portanto, conclui-se que os depósitos tecnogênico-sedimentares referidos e sua expressão geomorfológica são, geologicamente, registros correlativos desse processo de degradação paisagística, e arqueologicamente registros materiais da lógica predatória de 
apropriação do relevo, e assim da mentalidade de seus agentes, no contexto histórico referido. Que mentalidade era essa? O depósito nos diz que houve uma "lógica" predatória e destrutiva de apropriação do relevo, o que permite inferir que a interação com a natureza se fez de forma não "sustentável" em termos geoecológicos. Diz-nos também que essa "lógica" se configurou de forma episódica e transitória, porém intensa, em tempo relativamente muito curto mesmo em termos históricos (ou seja, não se configurando em processo de longa duração). Mas também permite sustentar a interpretação de uma mentalidade econômica imediatista, inconsequente e oportunista: podemos chamá-la de "mentalidade colonial". Vejamos sobre isso uma "analogia etnográfica":

Aos agricultores espanhóis, estabelecidos em Cuba, que queimaram as matas nas encostas das montanhas tendo conseguido com as cinzas daí resultantes o adubo suficiente para uma só geração, para cafeeiros muito lucrativos, que Ihes importava o fato de que, mais tarde, os aguaceiros tropicais provocassem a erosão das terras que, sem defesas vegetais, transformavam-se em rocha nua? (ENGELS, 1991: 226)

Outras fontes, científicas, historiográficas e literárias, que não abordaremos extensamente aqui, podem qualificar nossas interpretações, e serem usadas de forma análoga aos estudos de arqueologia histórica. Tomemos por exemplo Euclides da Cunha que, escrevendo no início do século XX (portanto no período de decadência do ciclo cafeeiro no Vale), no capítulo "Entre as Ruínas" do livro Contrates e Confrontos, descreve os efeitos do desmatamento:

Sem mais a vestidura protetora das matas, destruídas na faina brutal das derribadas, [os morros] desagregam-se, escoriados dos enxurros, solapados pelas torrentes, tombando aos pedaços nas "corridas de terras" depois das chuvas torrenciais, e expõem agora, nos barrancos a prumo, em acervos de blocos, a rígida ossamenta de pedra desvendada, ou alevantam-se despidos e estéreis, revestidos de restolhos pardos, no horizonte monótono, que abreviam entre as encostas íngremes... (CUNHA, 1975[1907]: 193)

Da precisa descrição "geoambiental", que caracteriza os processos degradativos que movimentaram o material geológico das encostas, que veio a se acumular nos fundos de vale na forma de depósitos tecnogênicos, Euclides vai além, imaginando as impressões de um viajante ao qual venha "a visão retrospectiva dos belos tempos em que a vivenda senhoril pompeava triunfalmente no centro dos cafezais floridos", e que, prosseguindo pela paisagem deserta entremeada de casebres abandonados e "santas-cruzes" ao longo dos caminhos, se 
visse invadido pelas crenças (sobrenaturais) ingênuas dos caipiras, o que se justificaria "ao menos, como se, de fato, por ali vagassem, na calada dos ermos, todas as sombras de um povo que morreu, errantes, sobre uma natureza em ruínas" (CUNHA, 1975 [1907]: 196-197).

O mais de um século decorrido desde Euclides apagou a ampla maioria dos vestígios que esse viajante observou, uma vez que mesmo as marcas da erosão acelerada foram apagadas pelos processos geomorfológicos ou pelo uso do solo (notadamente a pecuária) subsequente. Efetivamente, os depósitos tecnogênicos são o registro mais expressivo preservado do complexo episódio socioambiental descrito. Mas, como registros não produzidos diretamente, ou propositadamente, seriam eles também parte da cultura material? Menezes (1983) lembra que a Arqueologia estuda os sistemas socioculturais, em termos de sua estrutura, funcionamento e comportamento ao longo do tempo, ou seja, sua mudança, e que a particularidade da abordagem arqueológica reside em que isto é feito de forma exclusiva ou preponderante com informação derivada de restos materiais (ou seja, a cultura material).

Já Hodder e Hutson (2003) comentam que a cultura material não simplesmente "existe", uma vez que é feita por alguém, e produzida para fazer-se algo, e desse modo não reflete passivamente a sociedade, mas a cria por meio da atuação dos agentes sociais. Temos aí a agência, a criação da sociedade mediatizada pela cultura material. Meneses (1983) entende por cultura material aquilo do meio físico que foi apropriado socialmente pelo homem, o que implica em intervenção, modelagem e conformação de elementos do meio físico de acordo com propósitos e normas culturais. Desse modo, para o autor citado, essa ação não tem caráter aleatório, casual ou individual, mas reflete padrões, e assim o conceito referido (de cultura material) abrange artefatos, estruturas, modificações da paisagem, coisas animadas (uma sebe, um animal doméstico) e, também, o próprio corpo.

Os depósitos sedimentares antropogênicos induzidos são, efetivamente, incorporações ao meio físico de elementos que, conquanto decorrentes não intencionais da atuação dos agentes sociais, tiveram origem em sua agência, e toda agência implica em consequências imprevistas ou indesejáveis. Portanto, são produtos geológicos associáveis à cultura material arqueológica tanto como qualquer artefato que, por ter se tornado refugo, tenha sido descartado. O relevo (paisagem) pode ser apropriado culturalmente, e neste caso também se incorpora à cultura material. No entanto, esta apropriação do relevo-paisagem (ecofato), quando tem como consequência (e geralmente tem) a geração de depósitos correlativos (os 
depósitos tecnogênicos, que por sua vez, como formações superficiais, também se incorporam à paisagem), resulta na criação de outra categoria arqueológica, o geofato.

\section{Considerações Finais}

Os depósitos sedimentares antropogênicos de caráter induzido têm atraído o interesse dos geólogos como registros correlativos da ação humana na transformação da fisiografia e da dinâmica da paisagem, e configuram, com os demais terrenos tecnogênicos de agradação, um estrato geológico humano de caráter planetário (ZALASIEWICZ, 2008), também referido como arqueosfera (EDGEWORTH, 2014; EDGEWORTH et al. 2015). O estudo de tal estrato é um campo de colaboração científica em aberto entre geólogos e arqueólogos.

\section{Referências}

BORJA BARRERA, F. Formaciones superficiales antrópicas: aportación al estúdio del processo holoceno de antropización de los sistemas naturales. Arqueologia Espacial, Teruel,: n.16-17, p. 29-39, 1993.

CAPELLARI, B.; PELOGGIA, A.U.G. Degradação ambiental, sedimentação tecnogênica e reajustamento da drenagem na bacia hidrográfica do ribeirão das Sete Voltas (Taubaté, SP). In: CONGRESSO BRASILEIRO DE GEOLOGIA, 46, 2012, Anais... SBG, CDROM.

COELHO-NETTO, A.L. Catastrophic landscape evolution in a humid region (SE Brasil): inheritances from tectonic, climatic and land use induced changes. Suppl. Geogr. Fis. Dinam. Quat. III, T.3, p. 21-48, 1999.

CUNHA, E. Contrastes e confrontos. Rio de Janeiro: Record, 1975 [1907], 253p.

DEAN, W. A ferro e fogo: a história e a devastação da Mata Atlântica Brasileira. São Paulo: Companhia das Letras, 1996, 484p.

EDGEWORTH, M. The relationship between archaeological stratigraphy and artificial ground and its significance in the Anthropocene. In: WATERS, C.N. et al. (Eds.), A stratigraphical basis for the Anthropocene. London: Geological Society, Special Publication 395, 2014, p. 91-108.

EDGEWORTH, M.; RICHTER, D. deB.; WATERS, C.; HAFF, P.; NEAL, C.; PRICE, S.J. Diachronous beginnings of the Anthropocene: the lower bounding surface of anthropogenic deposits. The Anthropocene Review: v.2, n.I, p.33-58, 2015. Disponível em: http://anr.sagepub.com/content/2/1/33.full.pdf+html. Acesso em 23.06.2015.

ENGELS, F. Dialética da Natureza. $5^{\text {a }}$.ed. Rio de Janeiro: Paz e Terra, 1991, 238p.

FORD, J.R.; PRICE, S.J.; COOPER, A.H.; WATERS, C.N. An assessment of lithostratigraphy for anthropogenic deposits. In: WATERS, C.N. et al. (Eds.), A stratigraphical basis for the Anthropocene. London: Geological Society, Special Publication 395, 2014, p. 55-89.

GUIMARÃES, C.G. O café e a conta. Revista de História da Biblioteca Nacional, Rio de Janeiro: n.57, p. 24-26, 2010.

HAPP, S.C.; RITTENHOUSE, G.; DOBSON, G.C. Some principles of accelerated stream valley sedimentation. US Dep. Agr. Tech. Bull 695. Progress in Physical Geography, London: v.32, n.3, p.337-345, 2008 [1940]. 
HODDER, I.; HUTSON, S. Reading the past: current approaches to interpretation in archaeology. $3^{\mathrm{a}}$.ed. Cambridge: Cambridge University Press, 2003, 283p.

JAMES, L.A. Legacy sediment: definitions and processes of episodically produced anthropogenic sediment. Anthropocene: n.2, p.16-26, 2013. Disponível em http://www.sciencedirect.com/science/article/pii/S2213305413000040. Acesso em 23.06.2015.

LIMA, R.G.S. Café \& família no Vale do Paraíba. Revista do Instituto Histórico Geográfico do Rio de Janeiro, Rio de Janeiro: ano 12, n.12, p. 237-262, 2003.

MARTINEZ, P.H. Cultivo do desencanto. Revista de História da Biblioteca Nacional, Rio de Janeiro, n.57, p.28-29, 2010.

MELLO, C.L.; MOURA, J.R.S.; CARMO, I.O.; SILVA, T.M.; PEIXOTO, M.N.O. Eventos de sedimentação durante o Holoceno no Médio Vale do Rio Paraíba do Sul (SP/RJ) Aloestratigrafia e Datações por Radiocarbono. In: CONGRESSO DA ASSOCIAÇÃO BRASILEIRA DE ESTUDOS DO QUATERNÁRIO, V, Anais... ABEQUA/EDUFF, Niterói (RJ), 1995, p.193-200. Disponível em www.abequa.org.br/trabalhos/anais 1995.pdf. Acesso em 23.06.2015.

MENESES, U. B. A cultura material no estudo das sociedades antigas. Revista de História USP, São Paulo: n.115, p.103-117, 1983.

MOURA, J.R.S. E MELLO, C.L. Classificação aloestratigráfica do quaternário superior na região de bananal (SP/RJ). Revista Brasileira de Geociências: v.21, n.3, p.236-254, 1991. Disponível em: http://rbg.sbgeo.org.br/index.php/rbg/article/view/375. Acesso em 23.06.2015.

MOURA, J.R.S.: MELLO, C.L.; SILVA, T.M.; PEIXOTO, M.N.O. Desequilíbrios ambientais na evolução da paisagem: o Quaternário tardio no médio vale do rio Paraíba do Sul. In: CONGRESSO BRASILEIRO DE GEOLOGIA, 37, Boletim de Resumos Expandidos... SBG-SP, São Paulo, 1992, v.2, p.309-310.

NASCM - NORTH AMERICAN COMISSION ON STRATIGRAPHIC NOMENCLATURE. North American Stratigraphic Code. AAPG Bulletin, v.89, n.11, p.1547-1591, 2005.

OLIVEIRA, A.M.S. Depósitos tecnogênicos associados à erosão atual. In: CONGRESSO BRASILEIRO DE GEOLOGIA DE ENGENHARIA, 6, Atas... ABGE: ABMS, Salvador, 1990, v.1. p. 411-415.

OLIVEIRA, A.M.S.; BRANNSTROM, C.; NOLASCO, M.C.; PELOGGIA, A.U.G.; PEIXOTO, M.N.O.; Coltrinari, L. Tecnógeno: registros geológicos da ação do Homem. In: SOUZA, C.R.G. et al. (Eds.), Quaternário do Brasil. Ribeirão Preto: Holos, 2005, p.363-378.

OLIVEIRA, A.M.S.; PELOGGIA, A.U.G. The Anthropocene and the Technogene: stratigraphic temporal implications of the geological action of humankind. Quaternary and Environmental Geosciences, v.5, n.2. p.103-111. Disponível em http://ojs.c3sl.ufpr.br/ojs2/index.php/abequa/article/view/34828. Acesso em 23.06.2015.

PELOGGIA A.U.G.; OLIVEIRA A.M.S.; OLIVEIRA A.A.; SILVA E.C.N.; NUNES J.O.R. Technogenic geodiversity: a proposal on the classification of artificial ground. Quaternary and Environmental Geosciences: v. 5, n.1, p.28-40, 2014a. Disponível em: http://ojs.c3sl.ufpr.br/ojs2/index.php/abequa/article/view/34823. Acesso em 23.06.2015

PELOGGIA A.U.G.; SILVA E.C.N.; NUNES J.O.R. Technogenic landforms:conceptual framework and application to geomorphologic mapping of artificial ground and landscape as transformed by human geological action. Quaternary and Environmental Geosciences: v.5, n.2, p. 67-81, 2014b. Disponível em http://ojs.c3sl.ufpr.br/ojs2/index.php/abequa/article/view/34811. Acesso em 23.06.2015. 
PELOGGIA, A.U.G.; CAPELLARI, B.; SHIKAKO, A.S. Registros geológicos tecnogênicosedimentrares (antropocênicos) no Vale do Paraíba do Sul (Taubaté-SP): a aloformação Rio Una. In: SIMPÓSIO DE GEOLOGIA DO SUDESTE, 14, SBG-SP, Campos do Jordão, 2015 (submetido).

ROEHL, J.W.; HOLEMAN, J.N. Accelerated valley deposits. In: VANONI, V.A. (Ed.) Sedimentation Engineering. New York: Am. Soc. Civ. Eng., 1975, c.3, p. 382-389.

ZALASIEWICS, J. The Earth after us. Oxford: Oxford University Press, 2008, 256p. 